oxygen concentrations in the North Sea. They found that the intensity of seasonal oxygen depletion in highly stratified regions - where there is little mixing between layers of water of different temperature - has increased markedly since 1990.

In 2010, dissolved oxygen in the central North Sea and in an area known as the Oyster Grounds near the Dutch coast came close to ecologically critical values that, if reached, would require management action under the European Union's Water Framework Directive, the team reports. Biogeochemistry http://dx.doi. org/10.1007/s10533-0129729-9 (2012)

\section{EVOLUTION}

\section{Gene duplication for bigger brains}

DNA-duplication errors that upped the number of copies of a gene may have catalysed the evolution of complex brains in early humans.

The gene SRGAP2 is expressed during development of the brain's neocortex - a region involved in cognition. Evan Eichler at the University of Washington in Seattle and his team report that humans have four different versions of SRGAP2, as did Neanderthals, whereas other primates have just one. The group estimates that successive duplications of SRGAP2 occurred between 3.4 million and 1 million years ago, as Homo species evolved.

Meanwhile, Franck Polleux at the Scripps Research Institute in La Jolla, California, and his team show that one of the newer versions of the gene, SRGAP2C, blocks the activity of the ancestral SRGAP2 when it is artificially expressed in the brains of mice. Mouse neurons expressing SRGAP2C develop features of human neurons, such as a denser array of projections called dendritic spines that forge connections with neighbouring neurons. The cells also migrated across the developing brain faster than normal mouse neurons.

The authors suggest that these changes, driven by the emergence of SRGAP2C, could have occurred in early humans, who had much larger brains than their ancestors. Cell http://dx.doi.org/10.1016/j. cell.2012.03.033; http://dx.doi. org/10.1016/j.cell.2012.03.034 (2012)

For a longer story on this research, see http://go.nature. com/osz4hk

\section{NANOBIOTECHNOLOGY}

\section{Radio remote control of genes}

Externally applied radio waves can be used to switch on a modified gene in a mouse, thanks to radiation-absorbing nanoparticles injected into the animal. The technique could enable researchers to activate cells and genes non-invasively.

Jeffrey Friedman at the Rockefeller University in New York and his team coated iron oxide nanoparticles with antibodies so that they bound to a cell-surface protein complex, TRPV1, that admits calcium ions to the cell at a temperature of $42^{\circ} \mathrm{C}$. The researchers used radio waves to heat the nanoparticles, which, in turn, heated TRPV1. Calcium entering the cell activated the gene for an insulin precursor, which had been modified to contain a calciumsensitive regulatory region.

In live mice, 30 minutes of radio-wave exposure boosted insulin and lowered blood sugar levels.

Science 336, 604-608 (2012)

\section{BIOPHYSICS}

\section{High-throughput cell stretcher}

A chip on which cells flow through tiny channels can be used to measure the size and deformability of individual cells at a rate of 2,000 per second - several orders of magnitude faster than existing methods. The chip could be used to detect cancer cells, which are more deformable than healthy cells.

Dino Di Carlo and his team

COMMUNITY CHOICE

The most viewed papers in science

DRUG DELIVERY

\title{
On-demand drug release
}

\section{HIGHLY READ \\ on pubs.acs.org in April} a way to get drugs deep into tissues

Drug-carrying nanoparticles that shrink and release their payload when irradiated with ultraviolet (UV) light could offer and to unleash them on demand. This could be a valuable therapeutic tool for diseases such as cancer.

Currently available drug-delivering nanoparticles are at least 100 nanometres in diameter, which makes it difficult for them to squeeze into tumours. Daniel Kohane at the Children's Hospital Boston in Massachusetts and his colleagues made their particles out of organic molecules that switch conformation when hit with UV light. The nanoparticles were able to carry a number of drugs, including several used in cancer treatment, and shrank from roughly 150 to 40 nanometres under UV light. Irradiated particles released their drug cargo at a higher rate and diffused farther through both a collagen gel and corneal tissue than those not exposed to UV light.

J. Am. Chem. Soc. http://dx.doi.org/10.1021/ja211888a (2012)

at the University of California, Los Angeles, developed the microfluidic device, which suspends cells single-file in a liquid, stretches them, and then uses automated image analysis to measure their size and rigidity. The team detected cancerous cells in samples from patients with a sensitivity of $91 \%$ and a specificity of $86 \%$. The researchers were also able to classify stem cells on the basis of their deformability. Proc. Natl Acad. Sci. USA http://dx.doi.org/10.1073/ pnas.1200107109 (2012)

\section{EVOLUTION}

\section{Cheating cuts offspring fitness}

'Monogamous' female birds often produce young with another partner. This was presumed to yield offspring fitter than those produced with the paired partner, but a study of song sparrows suggests that 'cheating' comes with no evolutionary reproductive benefit.

Jane Reid at the University of Aberdeen, UK, and her team analysed 17 years' worth of genetic parentage data

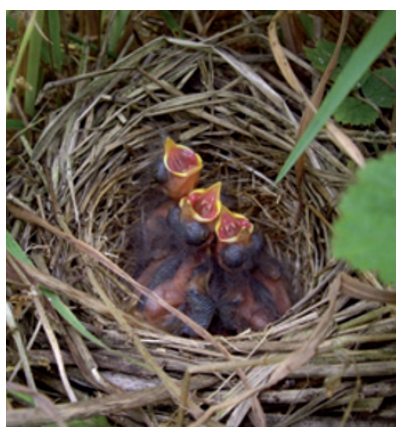

from a small population of song sparrows (Melospiza melodia; nestlings pictured) on Canada's Mandarte Island. They compared the lifetime reproductive success of half siblings with the same mother and found that young sired outside of monogamy were less reproductively fit than their half-siblings, producing on average $40 \%$ fewer offspring and 30\% fewer grand-offspring.

The researchers suggest that there may be indirect selection against, not for, cheating in song sparrows.

Am. Nat. http://dx.doi. org/10.1086/665665 (2012)

\section{$\rightarrow$ NATURE.COM}

For the latest research published by Naturevisit:

www.nature.com/latestresearch 